\title{
Cities and migration: generative urban policies through contextual vulnerability
}

Valeria Monno ${ }^{1 *}$ and Silvia Serreli ${ }^{2}$

\begin{abstract}
This paper deals with the relationships between urban policies for the integration of migrants and the construction of new spaces of coexistence in the contemporary city. It discusses the limits of the current conceptual framework of integration and shows how it works in a way that seperates space and people from each other. This creates marginalisation and segregation in already unjust and uneven cities. By contrast, the paper proposes a different perspective toward the construction of coexistence between local populations and migrants. It places a particular emphasis on contextual vulnerability and on its role in generative planning experiments that are aimed at creating inclusive cities. It also reflects on some of these experiences by considering their potential to reconnect local people, migrants and places, and shows how a focus on a relational and embodied understanding of vulnerability can give rise to supportive, less disciplining forms of coexistence in the contemporary city.
\end{abstract}

Keywords: Migration, Contextual vulnerability, Supportive coexistence, Generative policy making

\section{Introduction}

In Europe and in Italy, the recent refugee crisis has shown the structural weaknesses of urban policies which are aimed at integrating migrants into host societies (Coulibaly et al. 2019). Such a failure is inscribed in the confinement of migrants in camps as a result of reception policies, as well as in the segregation and marginalisation of migrants in urban areas where physical degradation and/or inequalities-and more generally social problems-abound.

Rather than being oriented toward integration, reception policies have segregated migrants and refugees in camps with the aim of controlling, regulating and diluting their arrivals as well as their impact on cities, and of avoiding conflicts with local host populations. Wherever localized the camps have often become "spaces of exception" (Agamben 2005) in which human rights are ignored and deemed meaningless. Hence, the very existence of the camp as an image of the reception of migrants has challenged the idea of the city as an open place and space

\footnotetext{
*Correspondence: valeria.monno@poliba.it

1 DICATECh, Politecnico di Bari, Bari, Italy

Full list of author information is available at the end of the article
}

which allows for the recognition of human dignity and for coexistence among strangers. At the same time, the permanence of migrants in cities, both during the reception period and after, unfolds in ways and places which have favoured their marginalisation and segregation rather than their integration. Since in many cases urban policies have primarily aimed at ensuring social support, migrants have often been easily relegated to areas that are no longer functional to those dynamics, logics and regimes of urban development that are associated with the dynamics of capital accumulation of neoliberal capitalism. The resulting urban landscapes are characterized by the segregation and marginalisation of migrants as well as by the erasure of the notion of the city as a place where everybody is entitled to having his/her rights of citizenships recognized.

These trends do not only favour the generation of peripheries within peripheries and marginalities inside already existing marginalities, but also of sharp levels of exclusion which nourish conflicts between local and migrant populations. In such a context, the arrival of migrants in small and large urban centers has not only been a source of disorientation for local settlers but has also brought about exclusionary and defensive behaviors 
(Sandercock 1998; Melotti 2007). In Italy, for example, the arrival of migrants has only been met with positive reactions in very few cases, such as in small towns where it has been perceived as a hope for contrasting processes of abandonment (Lo Piccolo 2014). Casting such exceptions aside, the situation of widespread intolerance and conflict in towns and cities is partly shaped by a set of more or less codified local practices of hospitality, which are designed to regulate the arrival and settlement of foreigners and the boundaries of integration (Gotmann 2004). However, it also depends on the lack of urban policies which are designed to confront complex problems that are linked to mass-migration and the inevitable formation of mongrel (Sandercock 2003), increasingly superdiverse cities (Vertovec 2014).

In this paper we argue that one of the factors that prevent cities from being places of coexistence is the absence of a spatial perspective within the existing frameworks for the integration of migrants which inspire urban policies and planning practices. Drawing on 4 years of intense discussions between the two authors, which concerned several activities and experiments carried out by the Department of Architecture, Design and Urbanism (DADU) of the University of Sassari between 2015 and $2018,{ }^{1}$ we advance the hypothesis that urban policies should be rethought in consideration of the vulnerability of places and people. This vision, which draws on a relational and embodied perspective toward urban space, takes the concept of contextual vulnerability to be central to the development of generative urban policies.

In what follows, we begin by discussing the inconsistencies of existing frameworks of integration, their repercussions on urban policies, and their resulting failure to make room for coexistence in cities. Next, we propose a relational and embodied perspective toward urban space, which focuses on contextual vulnerability as key for developing urban policies which are aimed at generating supportive coexistence. Finally, by reflecting on experiments which were carried out by the DADU with the aim of favouring the coexistence of young migrants and local inhabitants in Alghero, we describe the relevance of such an approach to urban policies.

\section{Urban policies and integration: a problematic pair}

Cities are not only central nodes in the migration processes: they are also crucial places where the integration of local populations and migrants may be realized. Due to the difficulties in finding efficient urban policies for the

\footnotetext{
${ }^{1}$ These Activities were carried out by Silvia Serreli, coordinator of Research Laboratory of LEAP_UNISS, (International Laboratory on the Environmental Project_with Giovanni Maciocco and Gianfraco Sanna).
}

integration of migrants at the local level, such a peculiar and strategic positioning of cities within migration flows has given rise to a renewed sense of urgency for action and for the construction of more appropriate frameworks of integration (OECD 2018).

Failures in the process of integration and the resulting lack of or partial inclusion of migrants into urban life have been often explained as a theory-practice gap which is due to an implementation deficit. Problems of coordination among different logics and steps in the integration process, ineffective multilevel governance arrangements, inefficacies of local administrations in implementing supra-national and national policies at the local level, pockets of resistance that are steeped in the settled population, and misinformation which opposes the process of construction of a multicultural society (Coulibaly et al. 2019) have surely hindered the diffusion of integration. Another cause of failure is also ascribed to the logic of control that permeates policies for the reception of migrants, and to its disconnection from urban policies which strive toward ensuring integration after life in the camp. Reception policies which aim to control, regulate and dilute the flows of migrants and their impacts on cities and local population, in most cases give shape to spaces of reception and "exception" (Agamben 2005) in which migrants live separated from the city and in a condition where their human rights are suspended. The very existence of the camp challenges the idea of the city as an integrative and open place which allows for the mutual coexistence of strangers. After sojourning in camps, the permanence of migrants within cities-whether stable or temporary, legal or illegal-unfolds in ways and places which restate their segregation rather than favour their integration.

However, the mass-migration of the last 5 years has also clearly shown that the inefficacy of current policies for the integration of migrants also depends on substantive issues that are related to the existing conceptual frameworks of integration that orient current approaches to urban policies (Cellini and Fideli 2002; Fieri 2009). In spite of the continuous revision of its contents, the conceptualisation of integration is still considered to be one of the most important causes underlying the modest results obtained so far. Surely, the conceptual framework of integration is now much more complex than it used to be in the past, when it alluded to a process of mere socio-economic assimilation. Multicultural and intercultural influences have introduced certain substantive changes into that framework and filled some of its crucial gaps, such as the need for recognition and the respect for differences, as well as for the right of inclusion of migrants in every aspect of urban life and in the democratic institutions of the host society. Above all, these 
perspectives have recentered the framework of integration on migrants as people and on the relevance of their interactions with a city's local population. In particular, participation, inclusion and coexistence among culturally and/or ethnically different persons and groups are now seen as indispensable features of the integration of migrants into host societies, which need to complement their socio-economic integration.

When observed at the ground level, for example in urban streets and neighbourhoods, and more generally in everyday life in both superdiverse (Vertovec 2007, 2010, 2014; Perrone 2018; Oosterlynck et al. 2018) and ordinary cities, this enlarged framework of integration appears as one of the many strands of rhetoric that tend to incorporate and control migrants rather than create coexistence. The prevalence of a vision of integration as a multi- or intercultural problem, and its underlying win-win perspective, which tends to obscure the highly uneven and unjust character of urban space, runs the risk of nurturing the formation of cultural enclaves in which integration depends on the vitality of tourism and leisure activities. Furthermore, the characteristics of migration and cities have changed over years and decades: nowadays, superdiversity (Crul 2016) and the culture of the camp highlight how public spaces are crucial to coexistence, and to the creation of micropublics through the spontaneous encounter among strangers (Amin 2002; Briata 2019). In such an evolving but also problematic context, crucial challenges to a still oppressive and control-oriented theoretical framework of integration (Uitermark 2014) should draw on and be grounded in everyday life and in planning practice at the local and, specifically, urban level.

Although formal urban planning has been quite indifferent to the problem concerning the integration of migrants, several micro-practices aimed at coproducing or creatively regenerating neighborhoods or public spaces have proved to be crucial in innovating approaches toward the integration of migrants, as well as redefining governance arrangements at an urban scale. They underscore that the experience of public space remains essential for shaping inclusive relationships between local populations and migrants in everyday life. Hence, creativity and coproduction have been considered as new avenues for imagining alternative or more inclusive forms of integration, beyond the separation between the reception and the long-term permanence of migrants in urban space.

Rethinking integration in relation to public space and on a small scale in a creative and coproductive way could prove effective in finding alternative pathways to integration, while also providing pragmatic solutions to urban conflicts and to migrants' needs. On the other hand, we argue that it is also necessary, whether at this small or at higher levels of action, to cope with another crucial but often overlooked problem which explains the seeming inevitability of failures in processes involving the integration of migrants. The contemporary rhetoric of integration sees cities and urban spaces as an inert background in the integration process and as a support where integration may occur depending on the individual capacity of migrants to fit in the host market/system and respond/ react to their own personal fragilities. Because current frameworks of integration ignore the fact that society and space are mutually constitutive (Bourdieu 1995; Massey 2005), urban policies and planning practice at any scale under the banner of integration reproduce urban landscapes which neither require calling into question the production of the city as a space for the accumulation of capital (Harvey 1985), nor redefine its content beyond its structural inequality and injustice. This separation also reinforces the production of the neoliberal city as a result of biopolitics (Foucault 1998) which writes off migrants, refugees and other outcasts as a social problem, as wasted lives (Bauman 2004), and as 'superfluous' populations. Based on this illusory separation between the social and spatial dimension of urban reality, the city is transformed into a series of urban contexts in which isolated individuals or groups interact while being unaware of the uneven and unequal web shaping urban socio-economic environments.

In such individualized and fragmented urban landscapes, which are designed through frameworks of integration that ignore the co-constitutive forces of places and people, migrants will experience the urban space as a barrier to integration, as an arena where they have to adopt specific 'tactics' (de Certeau 2009) such as moving with discretion and dissimulating their fear, or behaving as if they were in a scene from which they have to escape, or in a place which needs to be colonized and transformed by his/her cultural group in order to resemble their 'home city' or country. On the other hand, the local population feels as if they have lost their terrain, their 'home', if a foreigner 'occupies' the street they are walking down, or a house in their neighborhood, or 'intrudes' in his/her life while asking for charity at the traffic light.

While aiming to shape a cohesive society, the integration of migrants, thus construed, contributes to the constitution of vulnerable places and bodies even through small and seemingly insignificant acts and events in everyday life, which imperceptibly shape the urban landscape, the Other, and the tacit as well as explicit rules (de Certeau 2009) that give shape to integration in theory and practice. In these urban landscapes, migrants run the risk of being framed and written off (de Certau 2004) as the cause of social problems and conflicts. As a result, the unquestioned and pre-established duality and separation 
between people and places does not provide opportunities for changing regimes that generate vulnerabilities and underpin stigma, marginalisation and exclusion. In spite of various efforts toward promoting integration, social conflict and division will continue to reproduce themselves in the city.

As long as urban policies are oriented by a concept of integration which does not acknowledge the relational entanglement of spaces and people, migrants and local populations in the city will coexist in uneven and unjust urban landscapes. These landscapes are characterised by differential and polarized vulnerabilities in which migrants are excluded and marginalized and/or in which integration will result from a conditioned negotiation of values and rights. As we will see in the following paragraphs, a relational and embodied perspective toward urban space, which focuses on the vulnerabilities of places and bodies, can offer a relevant vantage point for identifying alternatives to existing frameworks of integration.

\section{Vulnerability as a key dimension of new urban policies}

The context that we have outlined so far shows how migrations make visible the profound political-institutional crisis in which urban policies and planning practices are embroiled, the cracks in current conceptual frameworks for thinking and acting (Friedman 1987, 2011; Sandercock 1998), and the parallel urgent need to change visions and institutions in order to produce urban spaces which are characterized by interactions based on an ethic of supportive coexistence (Carr et al. 1993). Since institutions are not mere organisational arrangements, but also include a set of more or less explicit norms, values and forms of reasoning and acting, changing visions and institutions for the integration of migrants requires enacting a profound change in the frames (Schön and Rein 1994) that orient existing urban policies and planning.

In order to overcome the absence of a spatial vision in urban policies, it could be useful to rethink migrants' integration from a different angle which assumes a relational and embodied understanding of vulnerability, and within which vulnerability expresses the co-constitutive character of places and bodies (Butler 2016). From our point of view, the vulnerability of bodies is part of the tacit dimension shaping the public culture of sociability.

From a relational perspective, a public culture of sociability can emerge in a "situated surplus" (Amin 2009) in which a condition of 'throwntogetherness' (Massey 2005) generates and makes room for the emergence and the experience of a culture of supportive coexistence. The latter cannot be exclusively reduced to a set of dynamics of interpersonal interaction that prompt a sense of 'us' or easen the interactions with the stranger: in situated surpluses "there is more at work, and in the form of influences that have more to do with the nature of the setting itself than the patterns of human association and sociality within public space. Therefore, [...] interaction is not a sufficient condition of public culture: it also has a tacit dimension that has to be acknowledged and is always mediated. The link between public space and public culture should be traced to the total dynamic-human and non-human-of a public setting" (Amin 2009). From our point of view vulnerability is one of the key aspects of the tacit dimension of public culture that has to be acknowledged and mediated to construct open interactions between migrants, local population and places.

We are aware that vulnerability is an ambiguous concept and that, if exclusively associated with the precariousness of each individual and place, it could obscure the causes of injustice, reproduce oppression, and activate passive behaviors that paralise individual and collective action (Butler 2016; Cole 2016). However, if approached from a relational and embodied perspective (Butler 2016, 2017), the vulnerability of places and bodies appears as a dynamic and mutable social construct. In particular, as Butler reminds us, a vulnerable body "is not a subjective disposition but a relation to a field of objects, forces, and passions that impinge upon or affect us in some way. As a way of being related to what is not me and not fully masterable, vulnerability is a kind of relationship that belongs to that ambiguous region in which receptivity and responsiveness are not clearly separable from each other, and not distinguished as separate moments in a sequence" (Butler 2016: pp 25). The vulnerability of bodies operates in a middle region between activism and passivity and can thus be mobilized as a means of resistance to oppressive forces (Butler 2016, 2017).

Therefore, aside from constituting a perspective from which we may understand ethics, agency, and subjectivity, as Butler (2017) has shown, the mobilisation of people's vulnerabilities within situated surpluses can give a new orientation to the 'virtues' of a situated surplus-namely openness, diversity, incompleteness, and its constitution as an improvised, and disorderly or lightly regulated crowd of things in a state of 'throwntogetherness'-in a way that is generative of social ethos with potentially strong civic connotations (Amin 2009). Re-writing urban landscapes in the age of migration by working through vulnerability may open up a different way of thinking urban policies in the city.

\section{The need for a generative approach}

Assuming a relational and co-constitutive perspective toward spaces and bodies that focuses on vulnerability 
suggests that supportive coexistence cannot be taken as a pre-given framework for shaping urban policies. Rather, the latter should draw on a generative approach which has inspired a wide set of bottom-up or spontaneous urban policies and practices ranging from insurgencies, to self-organisation, to more recent approaches to social innovation.

A generative approach adopts an action-based commitment that is intended to stimulate social change and alternative politics from below by making visible the invisible, and facilitating the inclusion of the tacit dimension of public culture that has to be acknowledged and mediated in order to construct open interactions between migrants, local population and places (Sandercock 1998). It sees the urban space as an uneven product and as a contentious arena that necessitates a collective proactive commitment to processes of urban transformation, and is animated by the tensions between the need for changing the existing status quo and planning theories and practice in use. It abandons the suffocating and paralyzing grip of leadership for the sake of discovering alternative urban policies, and defies techno-managerial postures in order to restore to people and policy making their value and capacity to make a difference (Monno 2016). It is a commitment to mobilize latent energies of change: in particular, those energies that are made invisible and/or ignored in the formal practices of production of urban space. A generative approach embraces an attitude toward planning that echoes a pedagogy of the oppressed (Freire 1986) in which planners are thought of as ignorant teachers, attentive listeners, lively mobilisers and weavers of energies which, in spite of being oppressed and/or latent, are carriers of supportive coexistence. Furthermore, a generative approach does not refer to a definite scale, or place of action. It can be mobilized in small places or at other scales of actionsuch as a deprived neighborhood or portions of decaying urban space-in which there is an urgent need for thinking beyond existing orthodoxies, out of the box, while looking for possible and impossible alternatives. It does not use predefined plans of action and deadlines.

In the case of uneven and unjust urban landscapes where the mariginalisation of migrants is at stake, a generative approach focuses on questions of embodiment. Here, it creates a public space in which a situated surplus-a situated multiplicity and throwntogetherness-exposes the vulnerability of places and bodies and copes with the uneven and unequal set of relationships that shape urban landscapes of migration and marginalisation. Such a situated surplus experiences and exhibits the complexity of those uneven and oppressive relationships through their embodiment in the everyday life. It mobilises transformative capacities, so as to oppose and change existing techno-managerial and marginalizing constellations and networks of actors (as well as values) which implement the existing framework of integration and give shape to individualized, oppressive and segregating urban landscapes. In mobilizing peoples' ideas and shifting the focus of action from 'power' to 'power with', a generative approach triggers dynamics of self-organisation that change rules and norms of interaction so as to give shape to novel institutions-even if only symbolic ones-by supporting new processes of sense-making and a new approach toward urban fragilities which is based on values of equity and social justice. It activates a process consisting in a continuous critical inquiry and in the activation of resources and people, which is aimed at making visible already existing but latent subjectivities, or at creating new ones. It is a self-organizing process that draws on a community-based conception of power (i.e. copower), that "develops through communal activity, for example, when the powerless join together in collective resistance to promote social change" (Guiner and Torres 2002 quoted in Hendriks 2009).

According to Arendt, power is a collective force that "comes into being only if and when men join themselves together for the purpose of action, and it will disappear when, for whatever reason, they disperse and desert one another" (Arendt 1963: pp. 174). Therefore, temporalities of emerging governance are part of a change which sets positive and creative energies free, and does not impose itself as an ever-present repressive force. Such governance arrangements exist when people are together and share something so as to become something else which connects people with something larger than themselves (Guiner and Torres (2002)). A generative approach is therefore constitutively a bridge towards a collective and ethical open future shaped by a sense of coexistence with diversity.

It differs from traditional practices of participatory and communicative planning because it embraces a perspective from which solutions to complex problems can only emerge from a collective proactive engagement with urban space and with its underlying dynamics of production. Activities and events from below, as well as storytelling, symbolic performances, and acts which involve the exposure of oneself and of one's body, such as mere walking, activate in that situated surplus tacit bonds which re-write the narratives of space. Generative urban policies and institutions regain a cultural role, as they not only work within a changing world, but are able to reorganise the public sphere and its underlying visions. Thus, from being a matter of resource distribution, urban policies and practices become a process of continuous activation of people and communities (Minervini 2016, p. 35), a continuous process that develops new forms of citizenship. 
To sum up, generative urban policy making is nothing but a fleeting network of relationships, norms and values that emerge through action in response to the absence of emancipatory visions of the city in the mass-migration era, which is dominated by techno-managerial and control-oriented logics of integration that inspire reception policies as well as urban policies which are designed to integrate migrants within cities. It promotes urban policies and planning practices which emerge by working with migrants and local populations in everyday life in order to capture energies of change and make sense of places in the mass migration era. It is a way to write new narratives of places and migrations through actions, to change marginalizing structures of interactions in the urban space and, accordingly, to create new institutions for a supportive coexistence.

\section{The relevance of contextual vulnerability}

European and, specifically, Italian policies for the reception of migrants coming from Asia and Sub-Saharan Africa have often been led by concepts of insecurity, and other hegemonic categories which have exerted a negative impact on the possibilities of coexistence between migrants and local populations in cities.

At the same time, various authors and research approaches emphasize the character of the 'migrant' as a vulnerable subject that is "predisposed to being easily attacked, or insulted" and is for this reason fragile. Following the insights of some scholars in the philosophy of right-and, among them, Thomas Casadei (2018) - we may say that migrants who cross the Mediterranean Sea in the direction of Europe are exposed to a twofold condition of vulnerability:

- a primary vulnerability, lying in their susceptibility to danger, understood as the exposure to the intrinsic risks of their journey;

- a secondary vulnerability, lying in the lack of capacities and resources for responding to the collision that is caused by their encounter with European sociopolitical and cultural reality.

If this twofold condition of vulnerability nourishes the politics of protection, it is also a source of hidden forms of stigmatisation and marginalisation of these subjects, who are thought of as weak people.

Drawing on this insight, this paper also interprets the recent processes of migration in consideration of such hidden prejudices, which arise when the vulnerability of migrants is understood in exclusively ontological terms (Levinas 1987) that is, as specifically inhering in the human condition (we are all indiscriminately vulnerable).
Following Casadei's categories of vulnerability, we may identify three conditions of vulnerability which migrants suffer, which have meaningful effects upon the modalities of reception and integration, and which we have had the chance to experience first-hand:

- a pristine vulnerability, which is determined by the inexperience and lack of awareness of the risks which the journey toward Europe may involve. This is the condition which migrants live through in their countries of origin, which is nourished by the illusion of Europe. Often, the encounter with the urban and social reality of a culture that is different from one's own becomes a real 'collision' which occasions forms of resistance on the part of migrants, in relation to possible forms of integration with the countries where they arrive.

- a willful vulnerability, when in spite of the awareness and the acknowledgment, the exposure to risks is deliberately neglected and calculated. In this case, one may also speak of a performance, on the part of migrants, of a 'culture of vulnerability': namely, the articulation of an idea of vulnerability which includes "a set of techniques of organisation and discursive techniques, through which the wide area of precarious contemporary lives may be confronted and managed, as much as possible" (Baroni and Petti 2014). This type of vulnerability reminds us of the urban condition in which certain 'social groups' (including migrants) are still marginalized. The city itself becomes vulnerable because it is incapable of contrasting the dimension of invisibility of such groups, and confines them in its enclaves of reception.

- deprived vulnerability, understood as the effect of the lack of disclosure, or use of useful information, for avoiding exposure to damage (e.g. marginality). Migrants are often exposed to three forms of vulnerability within shelters: "depriving someone or something of vulnerability means to subject them to sure risks, which will jeopardize their integrity, and deprive them of the possibility to defend themselves" (Casadei 2018: p. 82). In the enclaves of reception, the tie between vulnerability and protection becomes stronger: the intensity of systems of protection often exacerbates forms of dependence and justifies the marginalisation of those who are weak and incapable of being autonomous and of interacting with the surrounding context.

In these three situations, vulnerability is understood as an innate condition of these weak social groups: through the organisation of the 'camp', the current forms of institutional governance of reception generate a condition of 
permanent vulnerability and enforce a tight connection between vulnerability, wound, protection and cure.

However, if we adopt a critical perspective which accounts for the relational dimension of vulnerability (Zullo 2018), and therefore pay attention to its contextual character, migrants' condition of marginality and vulnerability does not merely imply living in a situation of deprivation, but potentially constitutes a way of accessing a radical dimension of openness (Casadei 2018). "Contextual vulnerability" is a condition that is peculiar to the life-context of an individual or of a group (Zanetti 2018). Considering vulnerability as contextual allows us to "explore society, or the institutions form which it originates, based on the fact that one of the reasons why individuals are vulnerable is that they are inevitably dependent upon cooperation with others, and upon the network of relations within which the idea of autonomy may be contextualized and realized in more specific terms" (Zullo 2016, p. 503 in Casadei).

Thinking of vulnerability from such a critical perspective allows us to expand our gaze from deprivation and marginality, to the construction of alternative relations within urban space.

This interpretation separates the concept of vulnerability from the idea of a permanent and unchangeable condition, and avoids the risk of introducing taxonomies that rigidly include or exclude individuals or groups from urban life. It thus allows us to think of migrants not as isolated individuals, but rather as subjects who relate to a definite context where they may enact dynamics of recognition, interconnection and interdependence with other subjectivities, with which they may share resources, conflicts, and spatiality. In short, a contextual understanding of vulnerability enables us to see migrants as active participants of urban life.

\section{Migration processes in Sardinia: the dimension of urban enclaves}

The context where the following experiments were carried out is Alghero, a small city of around 44.000 inhabitants in the province of Sassari-north Sardinia, which has been historically inhabited by a plurality of communities of foreigners, even more so than the southern part of the island. The reception and integration of migrants in this region began in 2014.

Until then, Sardinia had been a marginal transit land in the migration flows. As noted by Gentileschi (2005) at the beginning of this century European and nonEuropean residence permit holders in Sardinia totaled 11,265 , the $0.8 \%$ of the total number of temporary residents in Italy, and the $2.8 \%$ of island's resident population. However, Sardinia was also home to the highest average number of Africans who lived in Italy (34\% of the total number of immigrants) with a high concertation of Senegalese. Around 40\% of non-EU immigrants were concentrated in the two provinces of Cagliari $(37 \%)$ in the south, and Sassari, $6 \%$ in the north of Sardinia.

Because of the low number of migrants, the management of migratory flows and the reception and integration of migrants had been perceived to be much easier to accomplish than in other Italian regions and to be facilitated by the hospitality of local population.

This situation quickly changed in Italy and Sardinia after 2010. An increasing number of migrants arrived in Italy due to the political instability which swept across northern African countries, the escalation of wars in the Middle East, and other reasons, including the impact of climate change on poor areas of world. Data on migration flows in Europe show an impressive increase in the number of migrants' arrivals (especially in the period between 2014 and 2016), which soared from around 22.200 in 2013 to 186,600 in 2017.

In order to cope with this new situation the Italian Government changed its reception policies, which had been proved to be inefficient in responding to such a rapid increase of migrants arrivals. As a result, in 2015 (after that the National Legislative Decree $\mathrm{n}^{\circ} 142$ had passed in Parliament) the system of reception in Italy was reorganized in accordance with two kinds of reception centers. The first sort included CARA(Reception Center for Refugees and Asylum Seekers), CAS (Extraordinary Reception Centre) and CAR (Reception Centre). The second consisted in SPRAR, (Protection System for refugees and asylum seekers), which was meant to be organized and managed at the local level based on the willful commitment of local administrations, and to offer migrants (whether they be waiting for their permits or had already received them) housing and an entire set of other forms of support such as sanitary, social and language help. As a result, a lot of new CARA, CAS and CAR centres were opened in Italy and in Sardinia too, while SPRAR were activated only in very few cases.

As we have seen before, while different regions of Italy (Sicily, Apulia, Latium, Lombardy and Piedmont) had already experienced problems in the reception and integration of migrants, in Sardinia migration only turned out to be problematic in 2014 at the outset of the refugee crises and the opening of several CARA, CAS and CAR centres in this region which had no urban policies to deal with this new situation. As a result, in 2014 the National Committee for Asylum Seekers was set up in Sardinia (asylum seekers are those who, having left their country of origin and made a request for asylum, are waiting for a decision by the committee for a protection). 
Table 1 Asylum requests in Italy_Department for Civil Liberties and Immigration. Source: Our elaboration from quaderno_statistico_per_gli_anni_1990-2018.pdfDepartment for Civil Liberties and Immigration, Italy

\begin{tabular}{lllll}
\hline Year & Asylum requests & Males & \%males & Unreachable \\
\hline 2014 & 36.270 & & & 1095 \\
2015 & 71.117 & 64.906 & $91 \%$ & 4103 \\
2016 & 91.102 & 81.751 & $90 \%$ & 3084 \\
2017 & 81.527 & 70.581 & $87 \%$ & 4292 \\
2018 & 95.576 & 82.232 & $86 \%$ & 7740 \\
\hline
\end{tabular}

Migrants are 18-34 years old, and the majority of the fluxes have their origin in Bangladesh, Costa d'Avorio, Nigeria, Pakistan, Mali, Gambia, Ghana, Guinea, Senagal.

In Sardinia, the national government set up a Regional Territorial Commission in the city of Cagliari. Below is the institutional situation's summary of the numbers of people demanding asylum in the last 5 years (Table 1).

In July 2017, the province of Sassari had more than 2400 asylum seekers in the reception "camps", including 1900 men and more than 300 unaccompanied minors and over 200 women (source: Prefecture of Sassari). The buildings that have hosted the asylum seekers are often dismissed places (hotels, former barracks, companies, etc.) that have often exceeded their real capacity (Table 2).

Data from the Prefecture of Sassari show the capacity of the facilities, but more than their actual capacity has been used (e.g. 2600 capacity compared to an effective capacity of 1200). In 2018 this system of reception changed again and several centers were closed. Until then, the living conditions in several among reception centers of the first sort have been often problematic and assimilated to camps. Whether they be localized far away from or inside cities, these camps formed enclaves which revealed the fragility of urban space.

At the end of 2019 the total daily presences of asylum seekers in the CAS of Sassari Province were only 565 (Fig. 1).

\section{Experimenting generative policies through contextual vulnerability in Alghero} The choice of experiments

In Alghero and in Italy we can easily detect the fragile relations between cities and the recent phenomena of migration. As is well known, in the absence of adequate reception urban policies, this fragility is exacerbated by the obsolescence of traditional forms of sociality and by the absence of physical as well as mental spaces such as may stimulate the 'contact' (Choay 2003) between people in cities. This fragility is partly accounted for by the fact that the system for the reception of migrants in Italy is not structured to favour integration, and is neither prepared for an intensification of the inflow of migrants (economists speak of "a shock"), nor for sustaining the activity and continuity of a process of integration.

Among the many projects which in recent years were carried out by the Department of Architecture, Design and Urbanism (DADU) of the University of Sassari in order to cope with these issues, we focus in particular on two experiments involving some of the migrants sojourning in the city of Alghero, in northern Sardinia. They were hosted from 2015 until 2019 in an extraordinary reception centre (CAS), a former tourist facility located in the village of Fertilia in Alghero and hosting 65 migrants of different nationalities (Sahel region, North Africa, Bangladesh) who were aged between 17 and 28 years. The projects adopted a generative approach.

We choose as experiments to discuss University of Children for Un-Habitat (Entrenched Threads) and Fertilia in Movement ${ }^{2}$ because they took place in two particular kinds of urban spaces.

The former site is part of the urban archipelago of intermediate spaces of 'contact' where urban and social fragilities materialize both in the individual person, and upon mutually related subjectivities, thus shaping forms of interconnection and interdependence. In such an archipelago of spaces and situations, positive and negative 'collisions' come into being: that is to say that, within the urban space, certain 'contingent ententes' take place between different social figures, even when the subjects that come into play do not have a definite social role and therefore occupy a marginal position of vulnerability.

The latter experiment regards a situation of cohabitation in 'places of twofold abandonment'. These are places that have been forgotten by public policies and then abandoned because they have lost their attractiveness in the urban context due to the needs of the market (which erase spatial contexts that are no longer productive). Herein, the fragility of cohabitation generates conflicts among the different spatialities of the different communities.

Within these sites (which are not only present in Alghero but also in other cities) we had the opportunity to challenge the way in which, in the majority of cases, existing institutional models for the reception of migrants ignore the possibility of effecting integration as a result of the connection between spaces and people (Clemente 1974). In particular, both experiments mobilize the contextual dimension of vulnerability. This does not only involve an attempt to cope with vulnerability, understood as a sort of deprivation of agency, but above all to turn vulnerability into a new source of agency which is opened

\footnotetext{
${ }^{2}$ See: facebook \#FertiliainMovimento.
} 
Table 2 Asylum requests in Sardinia (National Commission for Asylum Seekers_Cagliari). Source: Our elaboration from quaderno_statistico_per_gli_anni_1990-2018.pdf_Department for Civil Liberties and Immigration, Italy

\begin{tabular}{|c|c|c|c|c|c|c|c|}
\hline Year & $\begin{array}{l}\text { Total requests } \\
\text { evaluated }\end{array}$ & $\begin{array}{l}\text { Protection } \\
\text { rejected }\end{array}$ & $\begin{array}{l}\text { Protection } \\
\text { accepted }\end{array}$ & Refugees & $\begin{array}{l}\text { Subsidiary } \\
\text { protection }\end{array}$ & $\begin{array}{l}\text { Humanitarian } \\
\text { protection }\end{array}$ & Unreachable \\
\hline 2014 & 650 & 472 & 178 & 51 & 38 & 89 & 34 \\
\hline 2015 & 2293 & 1933 & 361 & 52 & 79 & 230 & 97 \\
\hline 2016 & 3251 & 2116 & 1136 & 89 & 287 & 760 & 235 \\
\hline 2017 & 2874 & 1777 & 1097 & 100 & 111 & 886 & 3 \\
\hline 2018 & 2974 & 2068 & 906 & 85 & 86 & 735 & 5 \\
\hline
\end{tabular}

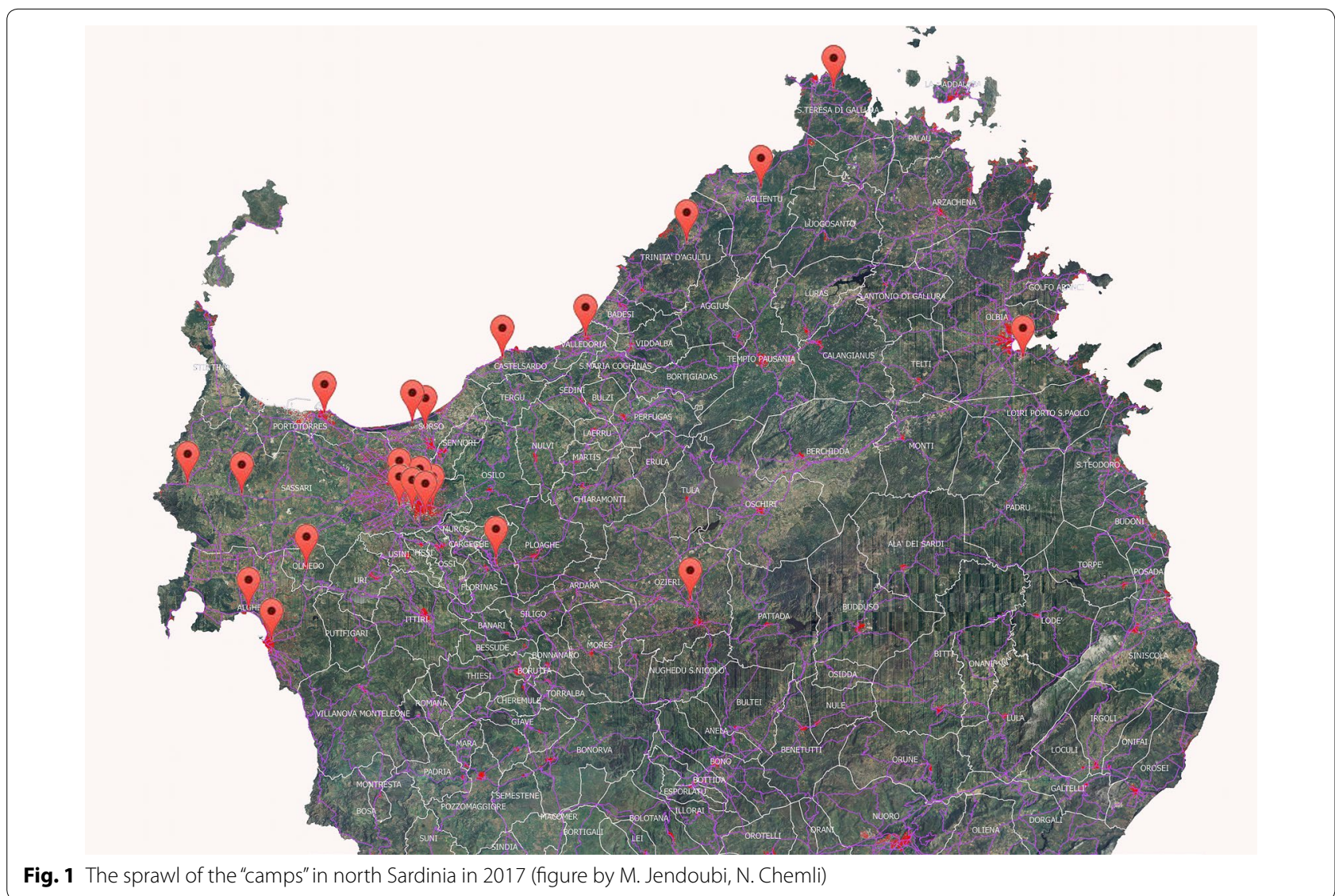

to coexistence. The events that we discuss below attempt to create a heretofore unexplored relationship between space and dwellers, such as may produce unexpected effects of empowerment for new migrating citizens.

The two experiments have been conducted by researchers and students of the Department of Alghero and other actors. Rather than using predetermined participative protocols and agreements the first case draws on the formative value of performative art and makes visible migrants' ability to assert their personal dignity and autonomy, and to acknowledge new spatial settings, even as they lie in situations of vulnerability. The second experiment may be described as a process of construction and deconstruction of public space that produces stable dynamics of connection and of intersubjective relations that assert the coincidental and variable character of vulnerability (Ferrarese 2009).

Fertilia in Movement involved students from DADU Alghero, citizens form Fertilia, the Alghero public administrations, different local associations and above all, the migrants (mostly refugees seekers) living in CAS Fertilia, Alghero. Through an intensive coordinated programme of actions-which included participatory meetings with the local population, educational and artistic 


\begin{tabular}{|c|c|c|c|c|}
\hline $\begin{array}{c}\text { Approaches } \\
\text { to } \\
\text { vulnerability }\end{array}$ & $\begin{array}{l}\text { Modes of } \\
\text { coexistence }\end{array}$ & Spatial configurations & Urban effects & Forms of governance \\
\hline \multirow{4}{*}{$\begin{array}{l}\text { Ontological } \\
\text { Vulnerability }\end{array}$} & & $\begin{array}{l}\text { Camp (temporary } \\
\text { reception) }\end{array}$ & & \\
\hline & Reception & $\begin{array}{l}\text { Diffuse welcoming } \\
\text { (SPRAR) }\end{array}$ & $\begin{array}{c}\text { Controlled } \\
\text { enclaves in reused } \\
\text { spaces }\end{array}$ & $\begin{array}{l}\text { Public institutions and } \\
\text { associationism }\end{array}$ \\
\hline & & & & \\
\hline & $\begin{array}{c}\text { Places of } \\
\text { twofold } \\
\text { abandonment }\end{array}$ & $\begin{array}{l}\text { Dismissed urban } \\
\text { buildings (and sites) for } \\
\text { precarious dwelling }\end{array}$ & $\begin{array}{c}\text { Physical and social } \\
\text { degradation } \\
\text { Lack of basic } \\
\text { services }\end{array}$ & $\begin{array}{c}\text { Forms of self- government, } \\
\text { Co-production }\end{array}$ \\
\hline $\begin{array}{l}\text { Vulnerability, } \\
\text { as a critical } \\
\text { perspective }\end{array}$ & $\begin{array}{l}\text { Spaces of } \\
\text { contact }\end{array}$ & $\begin{array}{l}\text { Public spaces } \\
\text { Spaces of education } \\
\text { Spaces of temporary } \\
\text { work }\end{array}$ & $\begin{array}{c}\text { Spaces of } \\
\text { coexistence } \\
\text { Collective spaces } \\
\text { of sense making } \\
\text { New services }\end{array}$ & $\begin{array}{l}\text { Networks of subjects and } \\
\text { institutions }\end{array}$ \\
\hline
\end{tabular}

Fig. 2 Ontological and critical vulnerability: spatial and governance configuration

activities, sport, and games-the events aimed at triggering the creative energies of students and researchers from the university, of teachers and children from primary and secondary school, of citizens and migrants, artists and volunteers, associations and institutional representatives (Fig. 2).

\section{University of children for un-habitat: entrenched threads}

The first experience highlights a concept of vulnerability which emphasises the inability of urban systems, and public of spaces in particular, to counteract the invisibility of migrants and the absence of a contact with local inhabitants. When they are outside the reception enclaves in Alghero (like other cities in Italy) opportunities for exchange with the local population are rare.

The experience which we carried out within the cultural project "University of Children's University of Sassari" (UBU) aims to stimulate an interface between university, school and city. It attempts some answers to transform the willful vulnerability-the condition of migrants in the spaces of the public city-in a contextual vulnerability that can enhance the individuality of migrants within a collective action in the urban space.

Various urban spaces emphasize the difficulty of dialogue between migrants and residents and subject the individual-migrant-but also the individual-inhabitant, the individual-child-to a condition of loneliness and insecurity. For this reason, we raised the question as to how public space may nowadays empower individuals, especially the most vulnerable (migrants but also children), and how it may valorize their role within the community.

This aspect has often been neglected in the analyses and the urban projects that concern the condition of the individual inhabitant, and daily practices of inhabitants.

During the activities promoted by the Department of Architecture, Design and Urban Planning for the third world conference of United Nations Human Settlements Programme, UN-Habitat, in February 2016, the University of Sassari's University of Children proposed an installation and participatory project with the aim of building an open and inclusive public space.

Working within the framework of a reflection and concrete action regarding the topic of multicultural coexistence in urban space, different performers-artists, children and migrants, teachers and local citizens-have produced an artistic performance in order to reinterpret the public space of a city square as a place of movement, mutual encounter and interaction. 
Public open space became the setting for the action in order to allow all participants to enjoy the square and learn its relevance as a historical place of Alghero (Juharia square represents one of the founding places of the city, the medieval Jewish settlement), and to stimulate them to imagine a different fate from the present one.

It is in fact a crossing space, which connects the buildings of the university in Alghero, but which lacks the strength of a space for rest, leisure and conviviality, in spite of its spatial qualities (such as its nearness the sea, to historical walls, the city's sea gate, etc.) and of the current regeneration intervention that has brought it back to the attention of the people of Alghero. Like other squares, it suffers from a loss of "contact" and re-signification, it is a place related to ephemeral practices that take place there periodically, rather than a space experienced by the city.

The experience involved fifty people including teachers, primary and secondary school children, university students, a group of young migrants from the Alghero reception centre, but also citizens of all ages. All the participants involved in the performance reconnected the square to its historical and recently built monuments (such as the historical wall, the university buildings, the public furniture, the metal safety stairs, etc.) through very long coloured threads (Fig. 3).

The threads built previously unimagined modalities of interaction which were aimed at designing novel entanglements. All participants were involved in Movement and play, thereby becoming makers of performative action. The great warp that was created under the guidance of artists turned the square into a series of labyrinthine paths, by placing strangers in relation with one another. Through play and individual creativity, the latter connected multiple threads: they connected people to one another, to objects, and to space, in order to stimulate their rooting in the territory. By weaving the threads with their own hands, participants were able to create novel spaces, new ways of moving, new thoughts and new interpersonal connections across the square.

For these reasons, the public performance stimulated the identification of different ways of perceiving and living space, and of designing its accessibility and usage (Serreli 2017). This presented people (and, especially, the most vulnerable inhabitants) with the opportunity of experimenting with the city, and of overcoming the state of deprivation which public space often gives effect to. Experiencing performance allows the meanings of place (as well as of community and of collective life) to resurface and expand. Such experimentation was authentic, and allowed people to express their inner capacity to plan, through their cooperation with others. The relationship between space, body and Movement created an environment of learning and endowed the public space of Juharia square with novel welcoming configurations, and most importantly presented migrants with the opportunity of establishing novel friendships and relational networks. Beginning from here, many of them began to undertake paths of real inclusion in the city and community of Alghero.

The affective, relational, sensorial and intellectual potentialities (Gardner 2010) which were stimulated in the subjects through the weaving of threads generated novel practices consisting in the use of space, by allowing migrants to engage in an effective exchange with a novel spatial context which lay outside of the reception centre. For this reason, as an interface between university, school and city, and thanks to the artist-led performance initiative, the UBU disclosed various formative opportunities, especially with regard to the topic of migration.

These experiences oriented children and grownups and involved them in new forms of self-generative learning regarding the obstacles that are often associated with the topic of migration, and to problems concerning migrants' ability to access urban and institutional public spaces. Furthermore, their direct encounter of young people that come from different countries is a sort of privilege for children, insofar as it activated a form of contact that could not have been realized within the context of institutional educational protocols. Performative actions express capacities that aid mutual communication, and allow for the emergence of "assemblage" (Deleuze and Guattari 1987: 88). The mobilisation of vulnerability weaves enduring threads of individual and collective experience, thereby laying out the conditions for the emergence of assemblages-in-action that constitute new networks of subjects whose interactions continue over time although assuming different configurations depending on the kind and modalities of action.

\section{Fertilia in movement}

The small town of Fertilia ${ }^{3}$ displays a twofold vulnerability, involving: (1) the presence, at its centre, of an archipelago of communities of refugees who come from different contexts that do not interact reciprocally; (2) the enclave constituted by the centre for the reception of migrants, which is isolated from the town and is subject to a variety of security-based constraints. Fertilia is

\footnotetext{
${ }^{3}$ Fertilia is a village of Alghero with less than 2000 inhabitants. It is one of the "new city" which was founded during the 1936 under the fascism and it is an example of the rationalist architecture and urbanism of that period. It was thought to settle emigrants from the province of Ferrara and then after the Second World War by exiles from Istria and Dalmatia. The localization of the CAS (Estraordinary reception centre) for migrants was seen as a risk of exacerbating peripherisation of this borough and marginalisation of migrants.
} 
a potentially intercultural setting, partly due to the presence of young migrants, who have experienced Fertilia itself as the first public place outside of the 'camp', as an urban environment where they may feel welcome in spite of the suspicion or the indifference of locals.

In Fertilia, the intense cooperation between different subjects from the community of Alghero and the DADU has generated a series of activities (within as well as without the CAS, between 2015 and 2017) which are aimed at offsetting dialogue between the cultures which the different nationalities of the migrant population stand for. When, in 2017, the CAS was shut to external visitors, due to the constraints imposed by new protection and security paradigms at the national level, the project "Fertilia in Movement", carried out by the DADU, was born in 2018. It prompted urban regenerative actions by activating the creative energies of students and teachers from the university, of teachers and children from primary and secondary schools, of citizens and migrants, artists and volunteers, associations and institutional representatives.

It was triggered by the reduction of resources available to migrants as a result of the newly implemented policies of reception. Furthermore, the project focused on the need to identify urban spaces for carrying on those activities and events which had hitherto allowed migrants to get into touch with the community of Alghero, and to avoid that the lack of contact with the local community would accentuate their vulnerability. At the time of the experiment, the only contact space left active was the School to which the young migrants "clung" in order to get out of the "camp".

Within the project of "Fertilia in Movement" an international workshop was developed in order to coordinate collective action for the purpose of meeting the need for public spaces devoted to intercultural activities. School, university and municipality, together with cultural associations, social cooperatives and a group of 30 young migrants (coming from the CAS, but also from SPRAR), engaged in factual cooperation aimed at regenerating public spaces in Fertilia. This effort lasted for several months during the preparatory stages of the workshop that took place in May 2018, which was attended by more than 100 people in an intense week of activity.

The principal action - which developed throughout the span of 1 week, and which was accompanied by a variety of parallel events-focused on site-specific setups with the aim of regenerating public spaces that were exclusively used by residents as crossing points; throughout the workshop, these were transformed into places for pausing and for inventing new experiences. In order to foster mutual encounter, and to overcome reciprocal mistrust between the various dwellers of Fertilia-the latter being especially connected to the presence of migrants-the workshop generated occasions for planning "together" (Sennett 2012) in situations of vulnerability and uncertainty, of obsolete radicalisms, and of continual movement of people and cultures which, in this very place that was deprived of communal ties, found hospitality.

The workshop encouraged the implementation of interventions that perhaps would not have been activated, had this cultural event not taken place. The isolation of migrants had generated within them a necessity for acting in order to contrast the new condition of vulnerability (understood as deprived vulnerability) and to establish stable connections with the city. Within this context, researchers from the DADU and teachers from the centre for senior education proposed the Municipality a programme of actions which were meant to unfold in those public spaces of Fertilia that were thought to be strategically important for favouring opportunities for mutual encounter and leisure. The workshop was in particular proposed as a moment of collective action aimed at the regeneration of a space within the state-owned pine grove and of a local sports field, these areas having been overlooked by the Municipality's public policies and having lain in a state of abandonment for several years. In this context, the young migrants proposed actions for self-construction invoking ephemeral spaces and structures originating from their material cultures.

The first area, the unused sports field, was made available to the young migrants and to the community of Fertilia. The Municipality created the conditions that were necessary for the purpose of overcoming bureaucratic obstacles and of rendering a strategic space accessible to migrants on a daily basis. The workshop provided the opportunity for an on-site effort which involved a first group, consisting of a team of technicians who focused on the removal of decaying items and of the shrub-like vegetation which had proliferated in the whole area, and a second group consisting of youth from the CAS who supported the reorganisation of the area and the organisation of an inaugural game of soccer.

The second area is the state-owned pine grove, which also lay in a state of abandonment due to the overlap between administrative competences which constitute a de facto obstacle to the regular maintenance and use of the area on the part of locals. During the workshop, more than 50 people, including teachers, students, local adherents to the project "active citizenship", migrants from the CAS and technicians from the Municipality, took part in a maintenance service of the pine grove by recreating spaces for accessing it and dwelling in it, and spaces dedicated to leisure activities. A sitting circle with a $100 \mathrm{~m}$ long circumference was realized by means of perishable materials in the state-owned pine grove. The circle (called kori by the young migrants), which represents 

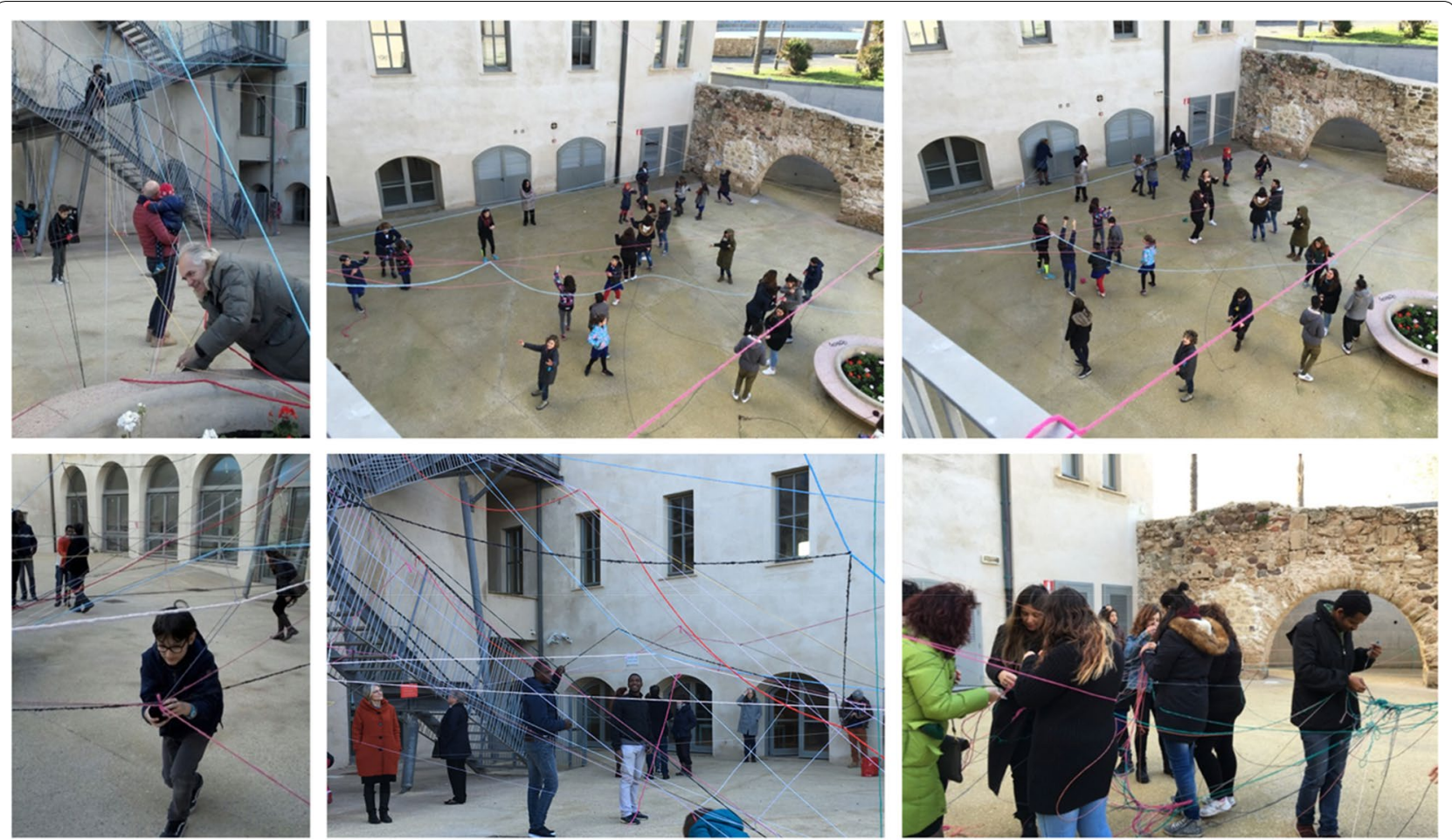

Fig. 3 Unhabitat

ideals of unity and of reciprocal encounter, constitutes an intermediate space of contact between the camp and the borough, and has highlighted migrants' condition of contextual vulnerability as a condition of interdependence between different subjects who are capable of removing the obstacles which are set by contemporary paradigms of security.

The meaning of space that was regenerated by the circle was revealed by the events which followed the workshop, thanks to artistic and musical performance, dancing, and educational activities that, throughout the following months, resorted to this space as a setting for regularly disclosing new perspectives. These events, which were also ephemeral, endowed space with a particular aura, carrying performers, students, migrants, and the various dwellers of Fertilia into a variety of spatial situations, at least for the whole duration of each event. In the absence of events and activities that resort to the circle, the space of the kori retains its representative strength, if compared to the state of neglect in which the space lay every day beforehand. What also endures is its value as a formative space which favours the feeling of motion (Berthoz 1998) which has slowly begun to transform behaviours and vulnerabilities. The significance of the circle, following the collective realisation that was activated by the process of self-construction and subsequent deconstruction, goes beyond its materiality and physical presence and expresses a meaning that transcends its form. It establishes a physical proximity that fosters the construction of a new reality, a third space that invokes other sorts of proximity, which are not necessarily spatial, nor tied to that place (Fig. 4).

\section{Reflecting on experience}

When reconsidered through the lens of the authors' work notes and memories of their discussions, of interviews and informal conversations that unfolded between the authors, migrants and the local population (both before and after the projects were carried out), as well as through work documents and photos, the experiments that we have described confirm the central role which a relational and embodied conception of vulnerability plays in the production of urban policies which are generative of supportive coexistence between local populations and migrants.

The mobilisation of vulnerability and in particular of migrants' contextual vulnerability which was accomplished throughout these activities transformed relationships of diffidence, indifference or conflict between migrants and locals into a newly entrenched and changing network of places, values, norms and actors that 
generated an unexpected situated surplus whose constituents were capable of performing actions of reciprocal support. The pivotal role which vulnerability played in shaping generative urban policies for us can be clearly discerned when the two experiments are re-examined through three interconnected categories of analysis, which express the generative potential of urban policies at the intersubjective, policy-making and spatial level.

When observed at an intersubjective level, vulnerability appears to have facilitated the emergence of a change in the way in which migrants, local population and places interact. The accomplished micro- and temporary transformations of places in which experiments took place show that actions of self-construction and deconstruction-such as those symbolized by the kori in Fertilia in Movement and by Entrenched Threads in Algheroencourage migrants and local populations to effect a change in the way in which they see each other, and in which they use and live urban spaces.

Working with and within vulnerable spaces in order to endow them with a new meaning, migrants mobilized their agency as a capacity of producing regenerated public spaces, thus giving a new image of themselves. The vulnerabilities of places and bodies have stimulated locals and migrants to interact with one another based on a novel awareness of those injustices and inequalities that are the root-causes of migration and which hinder coexistence in cities. Within this new framework of mutual interaction, the rights which migrants and local populations have been denied can be revealed, and their realisation can be offered meaningful support. Migrants were exposed to an empowerment process that gave new possibilities of life beyond the camp. Admittedly, the transformations of interpersonal relations which took place were largely confined to the group of people who participated in the conducted experiments. And yet, the narratives which these activities have inspired seem to have disclosed new opportunities for the mobilisation of individual agency and the diffusion of these forms of interaction across the entire city. Even after the completion of an event, after migrants and local populations have left a shared public space, and even as places and people seem to have forgotten the lesson of the events, still: the perceptual memory (Seremetakis 1994: pp. 129) of those experiences will remain entrenched in participants' everyday life, and thus bears the potential of impacting existing material and immaterial boundaries within/of a city, redefining the sense and the skyline of marginalisation and exclusion, and redesigning interactions between people and places.

At the level of policy-making, a more complex picture of the generative potentials that are linked to the mobilisation of relational and contextual vulnerability emerges from our analysis. As we have already seen in the above sections, the production of new urban spatialities that unfolded in the two experiments is mirrored by the emergence of novel assemblages that-following the lead of shared utopic ideas of hospitality-propose alternative models and new opportunities of inclusion, which call into play the sense of responsibility of local populations and, more and more often, of public institution. Although these assemblages faded away once the experiments came to an end, they seem to have facilitated the emergence of a self-organizing network of subjects. While the latter's shape undergoes changes over time, this network has involved on a stable basis migrants as well as volunteers, academics and cultural associations that are committed to intercultural dialogue. Their actions have given effect to an alternative form of governance-namely, self-organizing networked governance (Huppé et al. 2012)—which, while not being steered by public institutions, is tightly entrenched in the territory and is committed to the construction of urban spatialities which are characterised by supportive coexistence. While they have voiced informal support for the network, public institutions have nonetheless stayed outside of it. On the one hand, this behavior suggests that public institutions feel the need of coping with complex problems through forms of adaptive governance: while refraining from steering self-organising networks, institutions strive to stay tuned with them in order to take hold of their capacity to mobilise resources and to come up with innovative solutions (Huppé et al. 2012). On the other hand, we can recognize that self-organising networks are determined to retain their autonomy in order to maintain their generative openness and practice ways of governing cities and migrations which are alternative to the mainstream disciplinary culture of governance, which seems incapable of contrasting contemporary processes of production of peripheries within peripheries and of marginalisation within marginalisation.

To sum up: self-organising networked governance is a contextually-oriented and territorially-entrenched effort at solving concrete conflicts/problems regarding the interaction between local populations and migrants which is activated by co-power, and committed to contrasting marginalisation, and to promoting policies that are aimed at diffusing supportive ways of living in the city through the activation of the vulnerability of places and people. Its focus on the contextual dimension of vulnerability calls into question what may be referred to, following Sandercock (Key lecture, AESOP, Venice, 2019), as a shared "way of being on the earth" that draws on: the refusal of a culture which portrays integration as a matter of incorporation and oppression as an unavoidable feature of the urban interaction between people and place; 

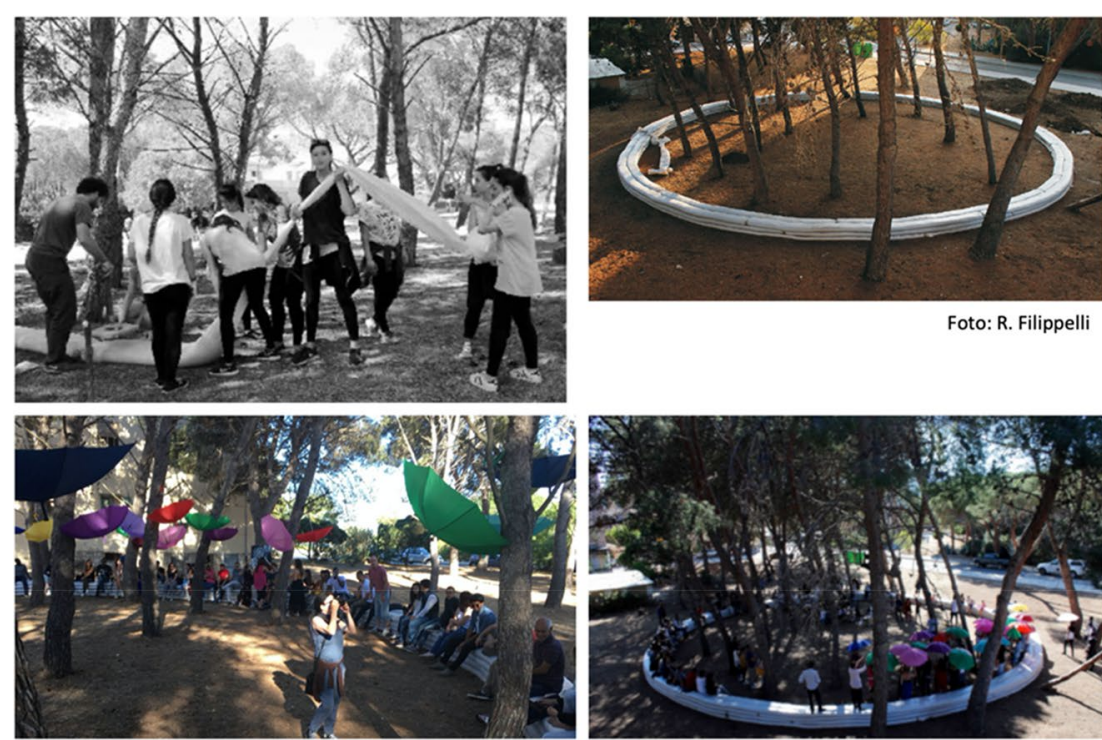

Foto: R. Filippelli
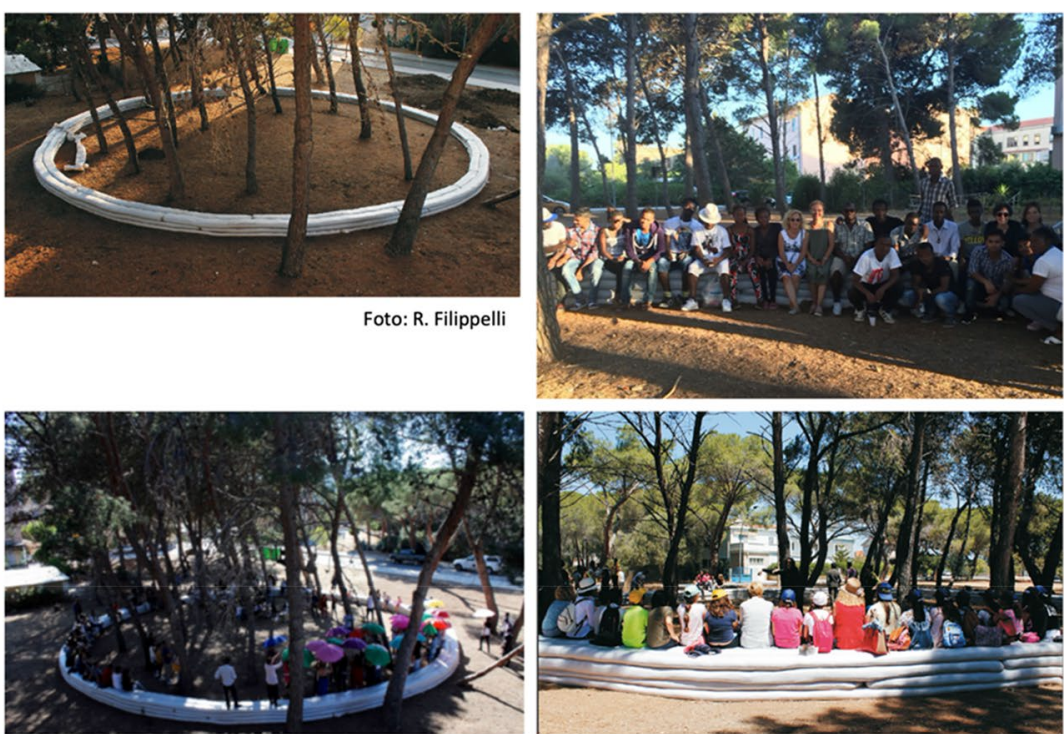

Fig. 4 Fertilia in movement

the refusal of a culture of extractivism which reduces human and non-human beings to mere disposable economic assets; and, finally, the rejection of the material and immaterial exploitation of the other (Mezzadra and Neilson 2017).

This transformed culture of governance is a way of being in the city which embraces emancipatory, sympathetic and transparent interactions, as well as a profound awareness of our reciprocally entangled destinies, in order to shape urban transformations in the everyday practice of city making. In spite of its temporarily character, this new culture has a diffusive and aggregative power which relentlessly questions dominating frameworks for the integration of migrants. In particular, the experiments of self-organized network governance which we have surveyed have enlarged existing frameworks of policy-making, by suggesting that integration does not only rely on the provision of basic services-such as housing, health care and education-to migrants, but also on a commitment to spatial justice and, specifically, on measures which aim at contrasting migrants' marginalisation.

At the same time, due to their ephemeral character, such experiments do not fit the requirements which public plans and programmes usually need to meet in order to benefit from available financial support. The Fertilia experiment also highlights the fact that changes which are undergone by non-codified policies and planning practices are often disregarded by public institutions, which prefer to stay outside of generative actions, so as to maintain the status quo and follow the flows of funding, rather than make change possible and remove the structural causes of marginalisation and vulnerability (Monno and Serreli 2018). Under these conditions, emergent networks and cultures of governance may lack the necessary strength for supporting the formation of durable ties of cooperation between local citizens and migrants which are needed in order to revitalize places like Fertilia (Fig. 4).

We are aware of these problems, and that these activities do not have the power to respond to certain urgent needs which relate to the material dimension of migrants' condition of marginalisation. At the same time, the experiments that have been described above show that generative actions can provide indispensable support to existing urban policies of integration. They offer a framework which strengthens, complements, and in some cases helps to implement existing policies that are specifically intended to ensure that migrants and/or refugees benefit from fundamental rights. In addition, they create supportive networks on which migrants may draw as they seek to find a house or a job. The two experiments also highlight tensions between dominant frameworks of integration and latent ones, whose potential to generate dynamics of supportive coexistence is yet to be reckoned with.

While, upon coming back to the sites where the events unfolded and where reconnections between people and places were forged, we can hardly find any signs of the latter's occurrence, they have changed locals' and migrants' mental maps of the city of Alghero. Shifting our focus to the spatial level, we may thus say that the aforementioned experiments write a different narrative concerning 
places, since they make visible the relationships that give shape to urban space, and redefine them as flows of power relations (Massey 2005) which are liable to being transformed. They change existing trajectories and flows by designing new urban geographies, where a new local culture of sociability perceives the co-constitutive character of the relationship between places and people. As a result, by drawing on a relational and contextual conception of vulnerability, these experiments restore to places their role as strategic and generative intermediate regions for action, where it is possible to affect the uneven and unjust structures that underwrite the dynamics of marginalisation of migrants within urban space.

As a result, by drawing on a relational and contextual conception of vulnerability, these experiments restore to places their role as strategic and generative intermediate regions for action, where it is possible to affect the uneven and unjust structures that underwrite the dynamics of marginalisation of migrants within urban space.

To conclude, we would also wish to highlight that, if considered together with other activities that were carried out by the DADU, the above experiments make room for change in the imageability (Lynch 1960) of a city, which includes dwellers' points of spatial reference, perceived spatial boundaries, customary pathways, and public spaces. The experiments were developed on a daily basis through an intense work of construction of possibilities for migrants, and for anybody in the city who was willing to take part in them. This sort of everyday commitment has changed the physical points of reference characterizing urban space-such as the university, restaurants, cafes, streets and pathways-which began to catalyse new practices of coexistence and became nodes of diffusion of a sense of co-power. Such a committed way of living changes the relationship between the local population and migrants and mitigates those conditions, discourses and practices that define migrants as passive vulnerable subjects, as strangers, or even as threats to locals.

All this suggests that focusing on vulnerabilities and enacting generative urban policies may help to foster the emergence of new ways of conceiving integration, which aim at consolidating new correspondences between the geography of everyday life and ways of sharing the city as a place of supportive coexistence.

\section{Authors' contributions}

The paper is a result of a joint research and an intense exchange of ideas. In it: "Introduction" section has been written by VM and SS; "Urban policies and integration: a problematic pair", "Vulnerability as a key dimension of new urban policies", "The need for a generative approach" sections have been written by VM; "The relevance of contextual vulnerability", "University of children for un-habitat: entrenched threads", "Fertilia in movement" sections have been written by SS; "Migration processes in Sardinia: the dimension of urban enclaves", "The choice of experiments", "Reflecting on experience" sections have been written by Valeria Monno and Silvia Serreli. All authors read and approved the final manuscript.

Funding

The research was not founded. It has been carried out by the authors. Article publishing is funded by DADU - Alghero University of Sassari.

\section{Availability of data and materials}

Not applicable. Our manuscript does not contain any data, please state.

\section{Competing interests}

The authors declare that they have no competing interests.

\section{Author details}

${ }^{1}$ DICATECh, Politecnico di Bari, Bari, Italy. ${ }^{2}$ DADU, Università di Sassari, Alghero, Italy.

Received: 10 December 2019 Accepted: 6 March 2020

Published online: 18 March 2020

\section{References}

Agamben G (2005) Il potere sovrano e la nuda vita. Homo Sacer. il Mulino, Bologna

Amin A (2002) Ethnicity and the multicultural city: living with diversity. Environ Plan A 34:959-980. https://doi.org/10.1068/a3537

Amin A (2009) Collective culture and urban public space. Public culture, June 2nd. https://www.publicspace.org/multimedia/-/post/collective-cultu re-and-urban-public-space. Accessed 2 Dec 2019

Arendt H (1963) On revolution. Viking, New York

Baroni W, Petti G (2014) Cultura delle vulnerabilità. L'homelessness e i suoi territori. Pearson Milano

Bauman Z (2004) Wasted Lives. Modernity and its outcasts. Polity Press, Cambridge

Berthoz A (1998) Il senso del movimento. McGraw-Hill, Milano

Bourdieu P (1995) Ragioni pratiche. II Mulino, Bologna

Briata P (2019) Multiculturalismo senza panico: Parole, territori, politiche nella città. FrancoAngeli, Milano

Butler J (2016) Rethinking vulnerability and resistance. In: Butler J, Zambetti Z, Sabsay $L$ (eds) Vulnerability in resistance. Duke university Press, Durham US, pp 12-27

Butler J (2017) L'alleanza dei corpi. Nottetempo, Milano

Carr S, Francis M, Rivlin L, Stone AM (1993) Public spaces. Cambridge University Press, Cambridge

Casadei T (2018) La vulnerabilità in prospettiva critica. In: Giolo O, Pastore $B$ (eds) Vulnerabilità. Analisi multidisciplinare di un concetto. Carocci Editore, Roma, pp 73-95

Cellini E, Fideli R (2002) Gli indicatori di integrazione degli immigrati in Italia. Alcune riflessioni concettuali e di metodo. Quaderni di Sociologia, pp. 60-84. https://doi.org/10.4000/qds.1345

Choay F (2003) Espacements. Figure di spazi urbani nel tempo. Skira, Milano

Clemente F (1974) (ed) I contenuti formativi della città ambientale. Pacini, Pisa

Cole A (2016) All of us are vulnerable, but some are more vulnerable than others, critical studies. Crit Horizons 17(2):260-277. https://doi. org/10.1080/14409917.2016.1153896

Coulibaly B, Herkrath M, Serreli S, Monno V (2019) Cities and cultures in movement. A pragmatic and place-based approach to social integration. In: Calabrò F, Della Spina L, Bevilacqua C (eds) New metropolitan perspectives. local knowledge and innovation dynamics towards territory attractiveness through the implementation of Horizon/E2020/Agenda2030 Volume 1. Springer, Hidelberg, pp 454-463

Crul M (2016) Super-diversity vs. assimilation: how complex diversity in majority-minority cities challenges the assumptions of assimilation. J Ethn Migr Stud 42(1):54-68. https://doi.org/10.1080/1369183x.2015.1061425

de Certau M (2004) La scrittura dell'altro. Cortina Editore, Milano de Certeau M (2009) L'invenzione del quotidiano. Edizioni Lavoro, Roma

Deleuze G, Guattari F (1987) A thousand plateaux. Capitalism and Schizophrenia. Trans. Massumi B. University of Minneapolis, Minneapolis 
Ferrarese E (2009) Vivre à la merci. Le care et les trois figures de la vulnérabilité dans les théories politiques contemporaines. Multitudes 2(37-38):132-141

Fieri (2009) Politiche urbane, sicurezza, discorso pubblico e inclusione degli immigrati. Città italiane e immigrazione. Ricerca coordinate da Teresa Caponio. https://www.fieri.it/wp-content/uploads/2008/03/Politicheurbane-sicurezza-discorso-pubblico-_16-dicembre-2009_.pdf. Accessed 02 Dec 2019

Foucault M (1998) The will to knowledge: the history of sexuality, vol 1. Penguin Books, London

Freire P (1986) Pedagogy of the oppressed. Continuum, New York, London

Friedman J (1987) Planning in the public domain: from knowledge to action. Princeton University Press, Princeton

Friedman J (2011) Insurgencies: essays in planning theory. Routledge, Abingdon

Gardner H (2010) Formae mentis. Saggio sulla pluralità dell'intelligenza. Feltrinelli Milano. English edition

Gentileschi ML (2005) The immigration model of Sardinia, an island and border region, Belgeo, Revue Belge de Gèographie, 1-2, pp 1-17. https:// doi.org/10.4000/belgeo.12526. Accessed 27 Nov 2019

Gotmann A (ed) (2004) Villes et hospitalitè. Les Municipalitès et leurs "étrangers. Éditions de la Maison des sciences de l'homme, Paris

Guiner L, Torres G (2002) The Miner's Canary. Enlisting Race, Resisting Power, Transforming Democracy. Harvard University Press, Cambridge (USA)

Hendriks CM (2009) Deliberative governance in the context of power. Policy Soc 28(3):173-184. https://doi.org/10.1016/j.polsoc.2009.08.004

Harvey D (1985) The urbanization of capital. Basil Blakwell and John Hopkins Unversity, Oxford

Huppé GA, CreecH H, Knoblauch D (2012) The Frontiers of Networked Governance, IISD, https://www.iisd.org/pdf/2012/frontiers_networked_gov.pdf. Accessed 10 Jan 2020

Levinas E (1987) Hors sujet. Fata Morgana. Montpellier. Italian edition Ciglia F P (1992) (ed) Fuori dal soggetto. Marietti, Genova

Lo Piccolo F (2014) Nuovi abitanti e diritto alla città. Un viaggio in Italia. AltraAlinea, Firenze

Lynch K (1960) The image of the city. The MIT Press, Cambridge

Massey D (2005) For space. Sage, London

Melotti U (2007) Immigrazione e conflitti urbani in Europa. Quaderni di Sociologia 43:115-139. https://doi.org/10.4000/qds.957

Mezzadra S, Neilson B (2017) On the multiple frontiers of extraction: excavating contemporary capitalism. Cult Stud 31(2-3):185-204. https://doi. org/10.1080/09502386.2017.1303425

Minervini G (2016) La politica generativa: pratiche di comunità nel laboratorio Puglia. Carocci, Roma

Monno V (2016) Activism and urban politics to come: escaping the acceptability trap. City Territoty Archit 3:25. https://doi.org/10.1186/s4041 0-016-0054-9
Monno V, Serreli S (2018) Progetti effimeri e possibilità di rigenerazione. In: Maciocco G, Lutzoni L, Valentino M (eds) Strutture generative e nuclei di urbanità. FrancoAngeli, Milano

OECD (2018) Working together for local integration of migrants and refugees, OECD Publishing, Paris. http://doi.org/10.1787/9789264085350-en

Oosterlynck S, Verschraegen G, Van Kempen R (eds) (2018) Introduction: Understanding super-diversity in deprived and mixed neighbourhoods. Divercities. Understanding super-diversity in mixed and deprived neighbourhoods. Policy Press, Bristol, pp 1-24

Perrone C (2018) Esperienze e politiche dell'accoglienza come possibile modello di rigenerazione territoriale. In: De Leo D, Caudo G, Innovare l'azione pubblica. Donzelli, Roma, pp 1-20

Sandercock L (1998) Towards Cosmopolis: planning for multicultural cities. Wiley, London

Sandercock L (2003) Cosmopolis II: Mongrel Cities in the 21st Century. Continuum, London

Schön D, Rein M (1994) Frame reflection: toward the resolution of intractrable policy. Basic Books, New York

Sennett R (2012) Together: the rituals, pleasures and politics of cooperation. Yale University Press, New Haven

Seremetakis N (1994) The senses still: perception and memory as material culture in modernity. University. Chicago Press, Chicago

Serreli S (2017) Territori formativi e progetti per nuove cittadinanze. In: Serreli S Calidoni P Città e formazione. Esperienze fra urbanistica e didattica, FrancoAngeli, Milano, pp 43-77

Uitermark J (2014) Integration and control: the governing of urban marginality in Western Europe. Int J Urban Reg Res 38(4):1418-1436. https://doi. org/10.1111/1468-2427.12069

Vertovec S (2007) Super-diversity and its implication. Ethn Racial Stud 30(6):1024-1054. https://doi.org/10.1080/01419870701599465

Vertovec S (2010) Towards post-multiculturalism? Changing communities, conditions and contexts of diversity. Int Soc Sci J 61(199):83-95. https:// doi.org/10.1111/j.1468-2451.2010.01749.x

Vertovec S (2014) Super-diversity. Routledge, London and New York

Zanetti GF (2018) Percezione e vulnerabilità. I cinque sensi come figure della vulnerabilità situata. Carocci, Roma

Zullo S (2016) Lo spazio sociale della vulnerabilità tra "pretese di giustizia" e "pretese di diritto". Politica del diritto 47(3):475-507

Zullo S (2018) Potenzialità e limiti della nozione di vulnerabilità nel dibattito bioetico-giuridico contemporaneo. In: Giolo O, Pastore B (eds) Vulnerabilità. Analisi multidisciplinare di un concetto. Carocci Editore, Roma, pp $187-200$

\section{Publisher's Note}

Springer Nature remains neutral with regard to jurisdictional claims in published maps and institutional affiliations.

\section{Submit your manuscript to a SpringerOpen ${ }^{\odot}$ journal and benefit from:}

- Convenient online submission

- Rigorous peer review

- Open access: articles freely available online

- High visibility within the field

- Retaining the copyright to your article

Submit your next manuscript at springeropen.com 